\title{
Imaging of Subcutaneous Ovarian Transposition and Its Rare Complications-A Pictorial Assay
}

\author{
Thara Pratap ${ }^{1}$ \\ K. Chithratara ${ }^{2}$ \\ ${ }^{1}$ Department of Radiology, VPS Lakeshore Hospital, Kochi, Kerala, \\ India \\ ${ }^{2}$ Department of Surgical and Gynaec Oncology, VPS Lakeshore \\ Hospital, Kochi, Kerala, India \\ ${ }^{3}$ Department of Internal Medicine and Rheumatology, VPS \\ Lakeshore Hospital, Kochi, Kerala, India
}

Muhammed Jasim Abdul jalal³

\begin{abstract}
Address for correspondence Muhammed Jasim Abdul Jalal, MBBS, DNB, MNAMS, MRCGP (UK), MRCP (UK), Department of Internal Medicine and Rheumatology, VPS Lakeshore Hospital, Nettoor PO, Maradu, NH 47 Bypass, Kochi 682040, Kerala, India (e-mail: jasimabduljalal@yahoo.com).
\end{abstract}

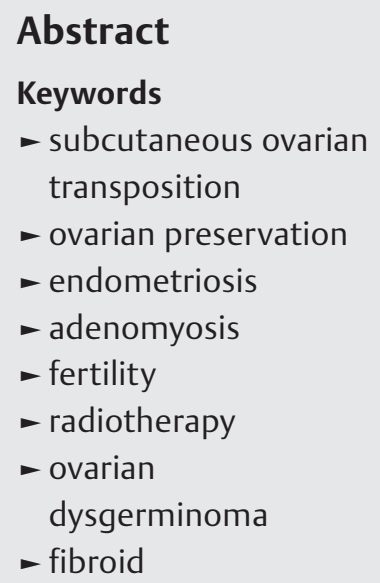

Ovarian transposition, as the name implies, is transpositioning the ovary from its normal anatomical position to another location. This procedure is usually done to preserve the ovarian function. The most common indication of ovarian transposition is early cervical cancer in young premenopausal women to preserve fertility. Subcutaneous ovarian transposition can also be done for benign conditions such as adenomyosis and severe endometriosis in young premenopausal women. We discuss our experience with ovarian transposition in 9 cases, normal ultrasound and CT imaging findings in transposed ovaries, and rare complications which occurred in 2 cases.

\section{Introduction}

Ovarian transposition is a rare procedure where the normal functioning ovary is repositioned from its normal anatomical position to another location in the peritoneum or retroperitoneum mostly to the lateral paracolic gutter or anterior to the psoas muscle above the pelvic brim or rarely in the subcutaneous region in the abdominal wall.

This procedure is usually done to preserve the ovarian function and hence preserve fertility and quality of life in young premenopausal women, mostly with early malignancy, who may require radiotherapy. The ovary, if healthy, can be transposed outside the radiation field by a simple procedure. Ovarian transposition can also be done for benign conditions like adenomyosis and severe endometriosis in young premenopausal women for easy ovum retrieval and to preserve fertility.

The surgical procedure is simple and can be performed mostly by laparoscopic method or open surgery. Laparoscopic reimplantation is less cumbersome compared with open surgery. It is done either with definitive surgery or as a separate procedure before radiotherapy. If ovarian transposition is done at the time of an extensive surgery, risk of vascular compromise may be higher. ${ }^{1}$

Either one or both ovaries can be transposed, though one ovary is enough to preserve the ovarian function. The position of transposed ovaries varies according to the extent of the radiation field planned.

Subcutaneous transposition was done in our center for 9 patients from 2014 to 2019 (-Table 1). The age group

\section{published online}

August 5, 2021
DOI https://doi.org/ $10.1055 / \mathrm{s}-0041-1731965$ ISSN 2581-9933 (c) 2021. Indian Society of Gastrointestinal and Abdominal Radiology. This is an open access article published by Thieme under the terms of the Creative Commons Attribution-NonDerivative-NonCommercial-License, permitting copying and reproduction so long as the original work is given appropriate credit. Contents may not be used for commercial purposes, or adapted, remixed, transformed or built upon. (https://creativecommons.org/licenses/by-nc-nd/4.0/). Thieme Medical and Scientific Publishers Pvt. Ltd. A-12, 2nd Floor, Sector 2, Noida-201301 UP, India 
Table 1 Summary of 9 patients who underwent subcutaneous ovarian transposition

\begin{tabular}{|l|l|l|l|l|l|}
\hline ID & Age, y & Year & Indication & Marital Status & Position \\
\hline Case 1 & 35 & 2017 & Adenomyosis with endometriosis & $\begin{array}{l}\text { Married, } \\
\text { nulliparous }\end{array}$ & $\begin{array}{l}\text { Subcutaneous, unilateral } \\
\text { right }\end{array}$ \\
\hline Case 2 & 29 & 2016 & $\begin{array}{l}\text { Carcinoma endometrium } \\
\text { FIGO 1a }\end{array}$ & $\begin{array}{l}\text { Unmarried } \\
\text { right }\end{array}$ \\
\hline Case 3 & 33 & 2018 & Adenomyosis with endometriosis & $\begin{array}{l}\text { Married, com- } \\
\text { pleted family }\end{array}$ & $\begin{array}{l}\text { Subcutaneous, unilateral } \\
\text { right }\end{array}$ \\
\hline Case 4 & 23 & 2017 & $\begin{array}{l}\text { Carcinoma ovary with deposits on the sur- } \\
\text { face of ovary/fallopian tube } \\
\text { stage 1c }\end{array}$ & $\begin{array}{l}\text { Married, } \\
\text { nulliparous }\end{array}$ & $\begin{array}{l}\text { Subcutaneous, unilateral } \\
\text { right }\end{array}$ \\
\hline Case 5 & 36 & 2018 & $\begin{array}{l}\text { Large multiple subserous leiomyomas where } \\
\text { preoperative diagnosis was spindle cell } \\
\text { neoplasm }\end{array}$ & $\begin{array}{l}\text { Married, com- } \\
\text { pleted family }\end{array}$ & $\begin{array}{l}\text { Subcutaneous, unilateral } \\
\text { right }\end{array}$ \\
\hline Case 6 & 31 & 2018 & $\begin{array}{l}\text { Intraepithelial neoplasia; endometrial malig- } \\
\text { nancy, FIGO stage 0 }\end{array}$ & $\begin{array}{l}\text { Married, } \\
\text { nulliparous }\end{array}$ & $\begin{array}{l}\text { Subcutaneous, unilateral } \\
\text { right }\end{array}$ \\
\hline Case 7 & 36 & 2019 & $\begin{array}{l}\text { Endometrial adenocarcinoma, FIGO 1a } \\
\text { Married, } \\
\text { nulliparous }\end{array}$ & $\begin{array}{l}\text { Subcutaneous, unilateral } \\
\text { right }\end{array}$ \\
\hline Case 8 & 27 & 2014 & $\begin{array}{l}\text { FIGO 1a adenocarcinoma } \\
\text { Married } \\
\text { nulliparous }\end{array}$ & $\begin{array}{l}\text { Subcutaneous, unilateral } \\
\text { right }\end{array}$ \\
\hline Case 9 & 31 & 2015 & $\begin{array}{l}\text { Married, not } \\
\text { completed } \\
\text { family }\end{array}$ & Subcutaneous, unilateral left \\
\hline
\end{tabular}

Abbreviation: FIGO, The International Federation of Gynecology and Obstetrics.
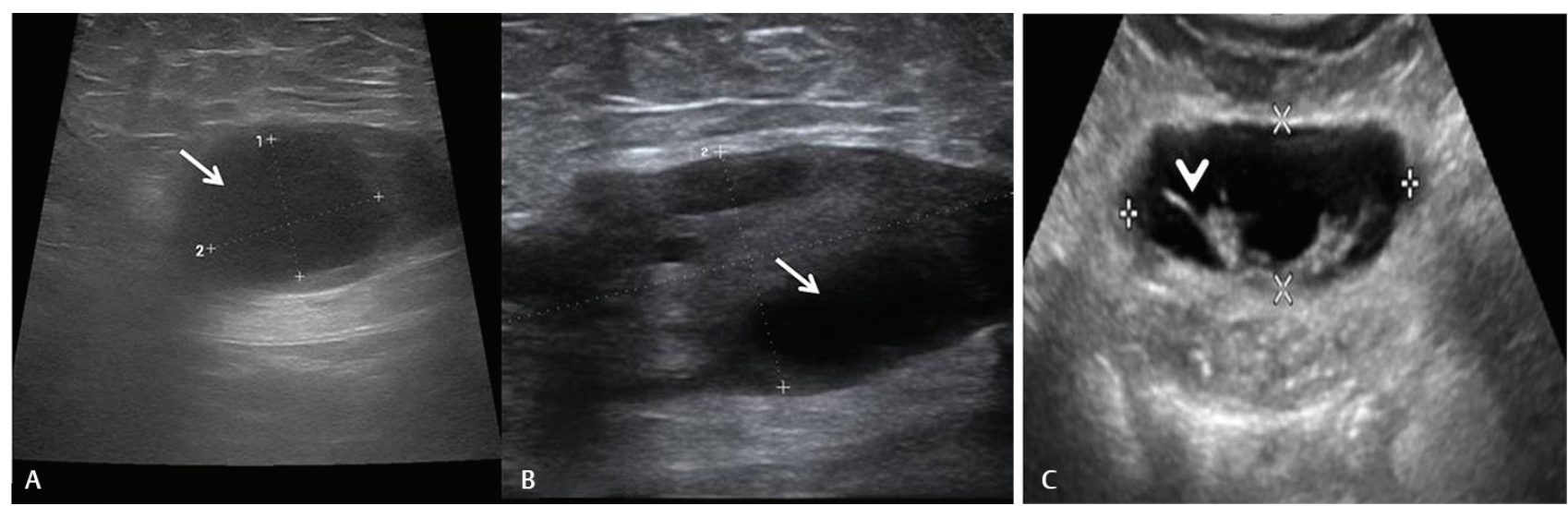

Fig. 1 (A--C) High-resolution ultrasound showing normal transposed ovary in the subcutaneous anterior abdominal wall in the right paramedian region showing normal ovarian follicles (arrow).

ranged from 23 to 36 years. Out of the 9 cases, 2 were of adenomyosis; one of uterine fibroid; one of ovarian dysgerminoma; and others of malignancy-cervical, endometrial, and ovarian. Of the 9 cases, there were complications only in 2 cases. We discuss the imaging findings of the normal transposed ovary as well as the rare complications.

\section{Surgical Procedure}

The ovaries and vascular pedicle were dissected from their ligamentous attachments to the uterus, mesovarium. Adequate length of vascular pedicle was secured and implanted either in the lateral abdominal wall or in the subcutaneous region.

The pedicle was brought out lateral to the cecum on the right side and lateral to the sigmoid-descending colon on the left side. Care was taken to ensure that the pedicle was not twisted. Fallopian tube was also removed. Literature search shows that to facilitate easy bringing out and positioning of the ovary in the anterior abdominal wall, the fallopian tube is not removed in some centres. ${ }^{2}$ The ovary was extraperitonealized in all the cases.

At our center, ovaries were positioned in the deep subcutaneous plane right or left paramedian infraumbilical region, so that they can be easily assessed on ultrasound scan (USS) with a high-resolution probe. This is to facilitate ovum retrieval as well as for the early detection of complications.

Normal imaging findings and shown in -Figs. 1-3.

All the patients were on regular follow-up with USS. Most of the patients were asymptomatic; however, on follow-up two patients developed complications.

We herein highlight the imaging findings of the complications of ovarian transposition in two cases. 

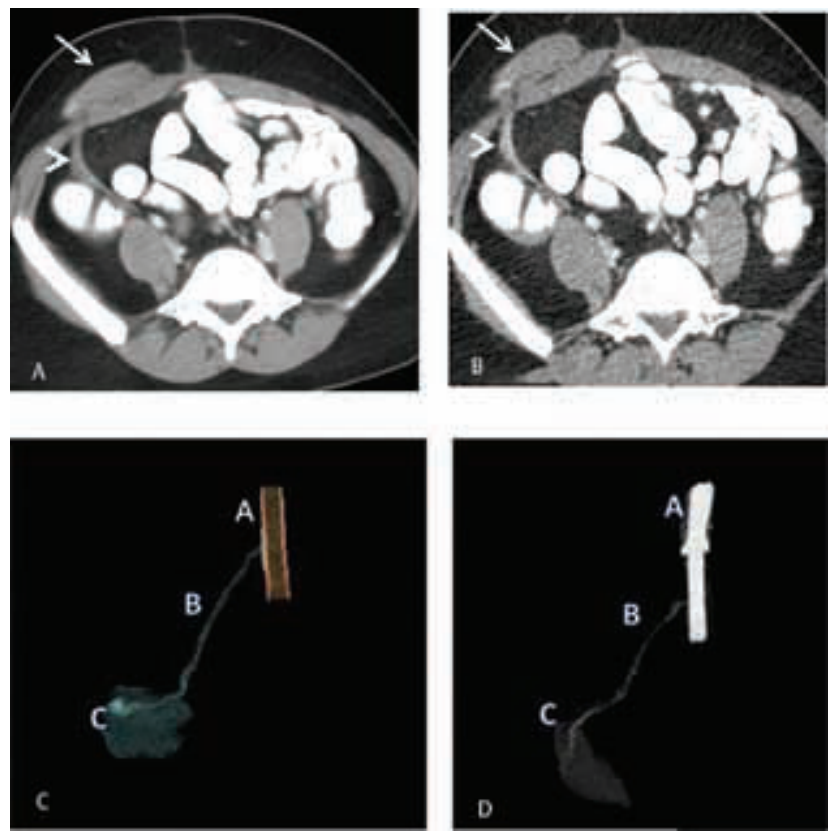

Fig. 2 (A, B) Contrast-enhanced computed tomography axial scans at the level of transposed ovary showing normal-sized ovary in the right paramedian subcutaneous fat (arrow) with pedicle containing ovarian artery and vein (arrowhead).(C) Three-dimensional angiography/(D) surface-shaded display showing ovarian pedicle with ovarian artery (A) arising from the lower aorta (B) supplying the transposed ovary (C).
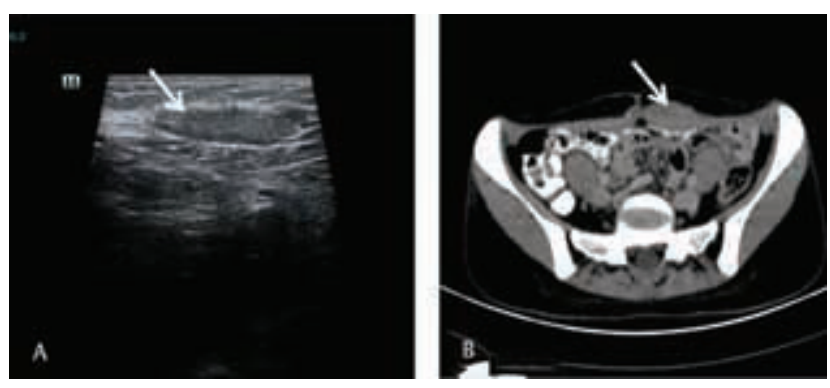

Fig. $3(\mathbf{A}, \mathbf{B})$ Normal transposed ovary in the left paramedian region on high-resolution ultrasound and axial CT (arrow).

\section{Case Report 1}

A 35-year-old woman who did not have any child had grade 3 endometriosis. She underwent total abdominal hysterectomy and left oophorectomy with right ovary transposition in the subcutaneous region of right iliac fossa. There were several causes for transposing the ovary rather than retaining it in the abdomen. She had severe endometriosis, with a possibility of endometriosis developing in the retained ovary. Also, there were dense peritoneal adhesions which might predispose to the development of peritoneal inclusion cyst. It was also considered reassuring that subcutaneous transposition would help in the early detection of endometriosis and, at the same time, give ease of surgical access if endometriosis develops.

-Fig. 4 shows high-resolution ultrasound images of the transposed right ovary in the abdominal wall. The ovary appears bulky with prominent follicles.
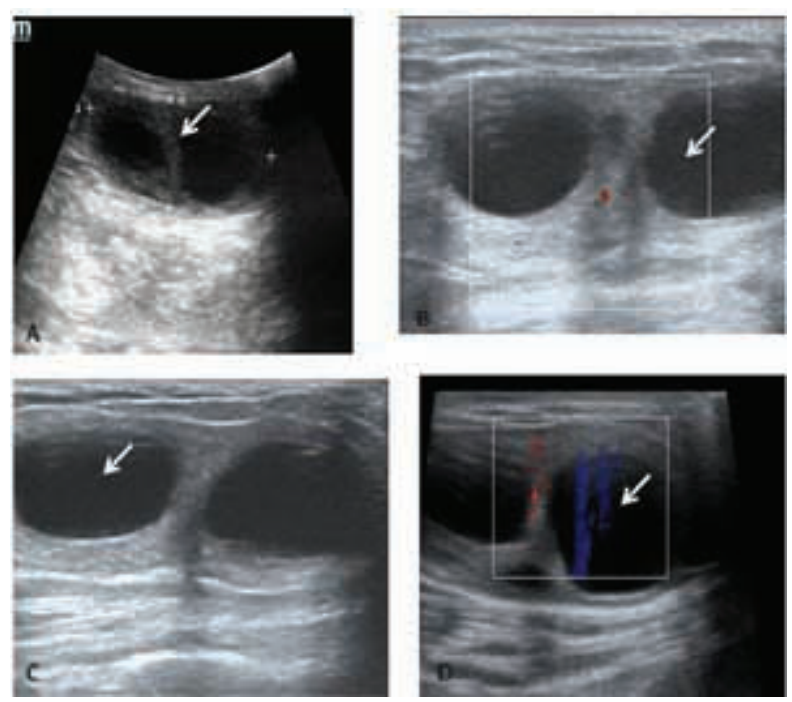

Fig. 4 Case 1: This 35-year-old woman who had not completed her family presented with severe endometriosis and underwent total abdominal hysterectomy and left oophorectomy with right ovarian transposition in the anterior abdominal wall. Transabdominal (A) and high-resolution ultrasound scan (B-D) shows mildly bulky right ovary with prominent ovarian follicles (arrow).

The patient was doing well but presented 3 years later with acute-onset right lower abdominal pain, abdominal distension, and 3 to 4 episodes of bilious vomiting. Contrastenhanced computed tomography showed normal transposed right ovary in the anterior abdominal wall. - Fig. 5 shows the bowel loops were dilated suggestive of subacute intestinal obstruction (SAIO) with transition at the distal ileal loop in the right iliac fossa ( $\mathbf{F}$ Fig. $\mathbf{5 E}, \mathbf{F}$ ). There was beaking at the transition zone with twisting of bowel loops around the transposed right ovarian pedicle. Transposed ovary was of normal size, in the anterior abdominal wall.

With a diagnosis of SAIO, due to adhesion and twisting of ileal loops around the ovarian pedicle, the patient was taken up for surgery, findings were confirmed, the twisting was released, and ovary was conserved. The patient has been asymptomatic after that and is on follow-up.

\section{Case Report 2}

A 29-year-old unmarried woman was evaluated for irregular bleeding per vaginam and polymenorrhagia, and was found to have an endometrial polyp. Polypectomy was done which was reported as endometrioid adenocarcinoma grade II. Ca 125 (10.4 U/mL) and CEA (0.59 ng/mL) were normal. Dilatation and curettage showed endometroid adenocarcinoma with areas of complex hyperplasia with atypia. Total abdominal hysterectomy was suggested but the patient was unwilling for surgery. Initial fluorodeoxyglucose (FDG) positron emission tomography (PET) CT did not show evidence of disease in the uterus or abdomen. Hence, hormone-eluting device (Mirena, Bayer. Whippany, New Jersey) was inserted and the patient was kept on follow-up. A year later, she presented with heavy irregular bleeding. Repeat FDG PET CT after a year showed ill-defined FDG-avid hypodense area in the 

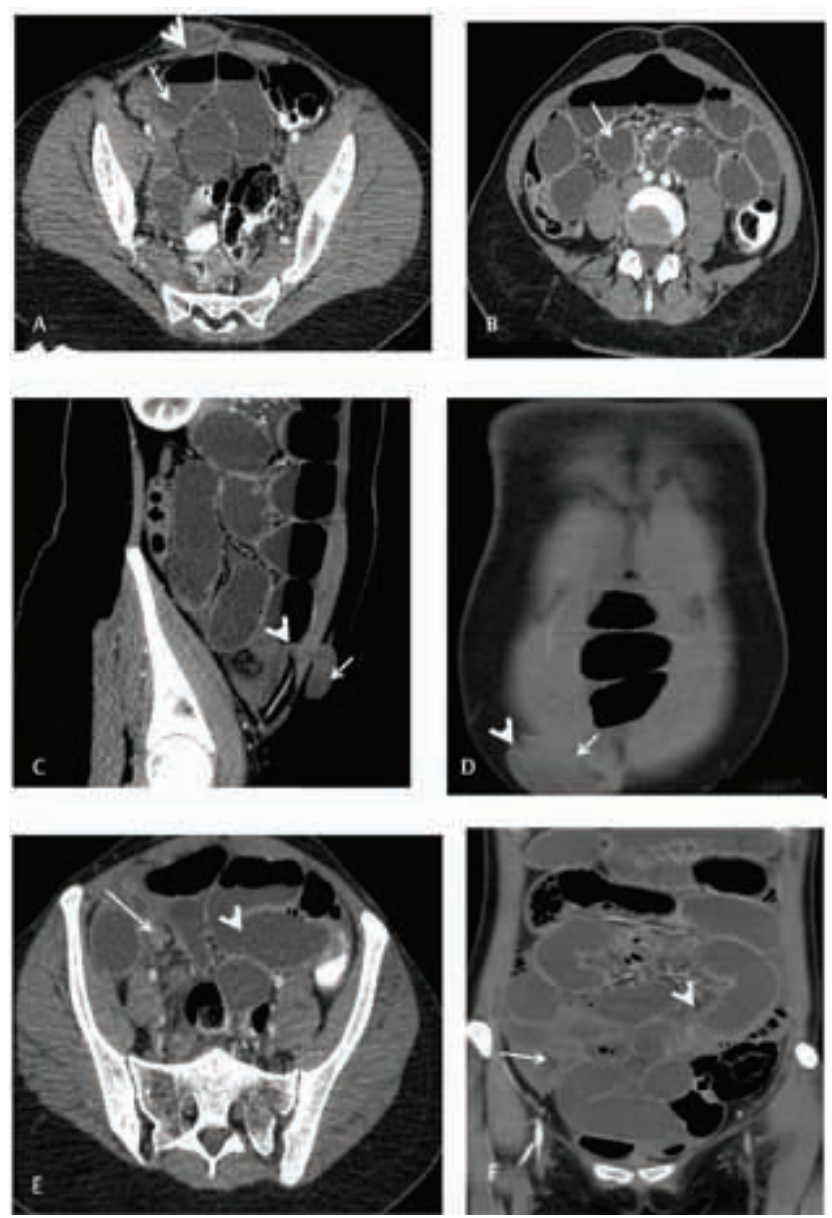

Fig. 5 (A, B) Case 1: After 3 years, the patient presented with abdominal pain and underwent contrast-enhanced computed tomography (CECT). Axial CECT shows dilated proximal and mid small bowel loops (arrow). The transposed ovary appears normal in size and is seen in the anterior abdominal wall right paramedian region (arrowhead). (C, D) Sagittal and coronal CECT shows the normal-appearing transposed ovary (arrow) in the subcutaneous fat with the pedicle (arrowhead). (E, F) Axial and coronal CECT scan of the same patient showing dilated small bowel loops (arrowhead) with transition at the RIF region (arrow) with collapsed small bowel loops distally. Case 2: A 29-year-old unmarried woman with endometrial carcinoma FIGO (The International Federation of Gynecology and Obstetrics) stage $1 \mathrm{~b}$, underwent total abdominal hysterectomy, left salpingo-oophorectomy, and right ovarian transposition. After 2 years, she presented with abdominal pain at the site of transposed ovary and hence PET CT was done. Axial FDG PET scan was performed. CT, computed tomography; FDG, fluorodeoxyglucose; PET, positron emission tomography.

endometrium, suspicious of recurrence. She underwent modified radical hysterectomy with left salpingo-oophorectomy + right salpingectomy + right ovarian transposition. Ovarian transposition was done to preserve fertility.

The final histopathology was endometrioid type-grade II tumor $\sim 5.5 \mathrm{~cm} \times 1.5 \mathrm{~cm} \times 1 \mathrm{~cm}$ in size, infiltration involving less than half of myometrium with no lymphovascular emboli. Right and left parametrium and paracervical tissue and bilateral pelvic lymph nodes were free of tumor. There was no distant dissemination. Endometrial carcinoma was staged as 1a (FIGO [The International Federation of Gynecology and Obstetrics] staging). The patient was on conservative management.
However, 2 years later, she presented with pain and enlargement at the site of transposed right ovary. Repeat FDG PET CT ( - Fig. 6A, B) showed mildly enlarged transposed ovary $(4.1 \mathrm{~cm} \times 2.2 \mathrm{~cm})$ with PET uptake (SUV) maximum 9.1 in the solid area, along with few enlarged mediastinal, prevascular, and external iliac nodes suspicious of recurrence. The patient denied biopsy. The size of ovary was gradually increasing in size. Another FDG PET CT ( - Fig. 7A, B) was done a year later and showed further enlargement in the size of the transposed ovary with solid-cystic appearance $(84 \mathrm{~mm} \times$ $80 \mathrm{~mm} \times 86 \mathrm{~mm}$ ), with FDG uptake and SUV of 19.7. PET scan also showed avid lung nodules and para-aortic nodes with other pelvic deposits, suggesting progression. Axial images ( - Fig. 7C, D) at the level of renal hilum, showing FDG-avid para-aortic nodes (arrow). Axial images (-Fig. 7E, F) at the level of pelvis, showing other peritoneal and abdominal wall deposits.

Trucut biopsy and histopathology from the transposed ovary was consistent with adenocarcinoma. The disease had disseminated by this time and hence she was started on chemotherapy with taxol and carboplatin.

\section{Discussion}

In young premenopausal patients with early malignancy where the ovaries are normal and can be preserved, ovarian transposition is an option to preserve the ovarian function. The ovaries are transposed outside the radiation field mainly to minimize the chance of ovarian failure.

Ovarian irradiation accelerates the natural process of follicular atresia, leading to premature menopause. ${ }^{3}$ Complete ovarian failure has been known to occur after radiation doses in the region of $20 \mathrm{~Gy}$ in women younger than 40 years and after $6 \mathrm{~Gy}$ in older women. Ovarian transposition is 44 to $85 \%$ effective in preserving ovarian function. ${ }^{4}$

Literature search shows that ovarian transposition is mostly done for early cervical cancers; few cases have been done for vaginal cancer and nongynecological causes like rectal cancers, sarcoma, and lymphoma which require pelvic irradiation. The most common indication of ovarian transposition is early cervical cancer in young premenopausal women.

Guo et al performed ovarian transposition in 34 patients from August 1989 to December 2000. Apart from malignant
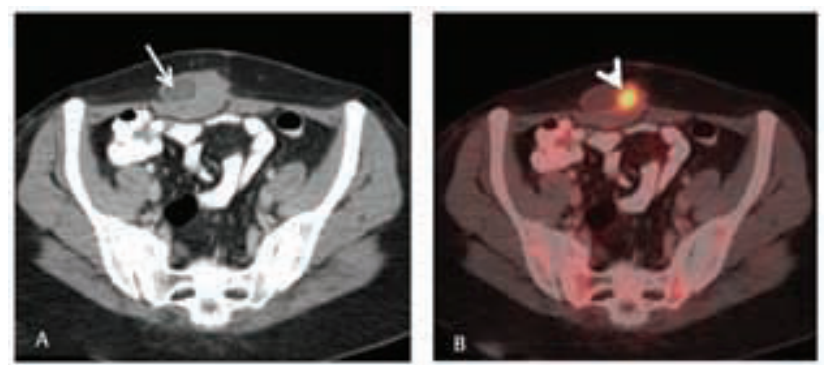

Fig. 6 (A) Transposed right ovary in the anterior abdominal wall with follicle (arrow) and PET uptake with SUV of 9.1 in the solid area (arrowhead). The patient had denied biopsy. (B) Case 2: The lesion was gradually increasing in size. After a year, a repeat FDG PET CT was done. 

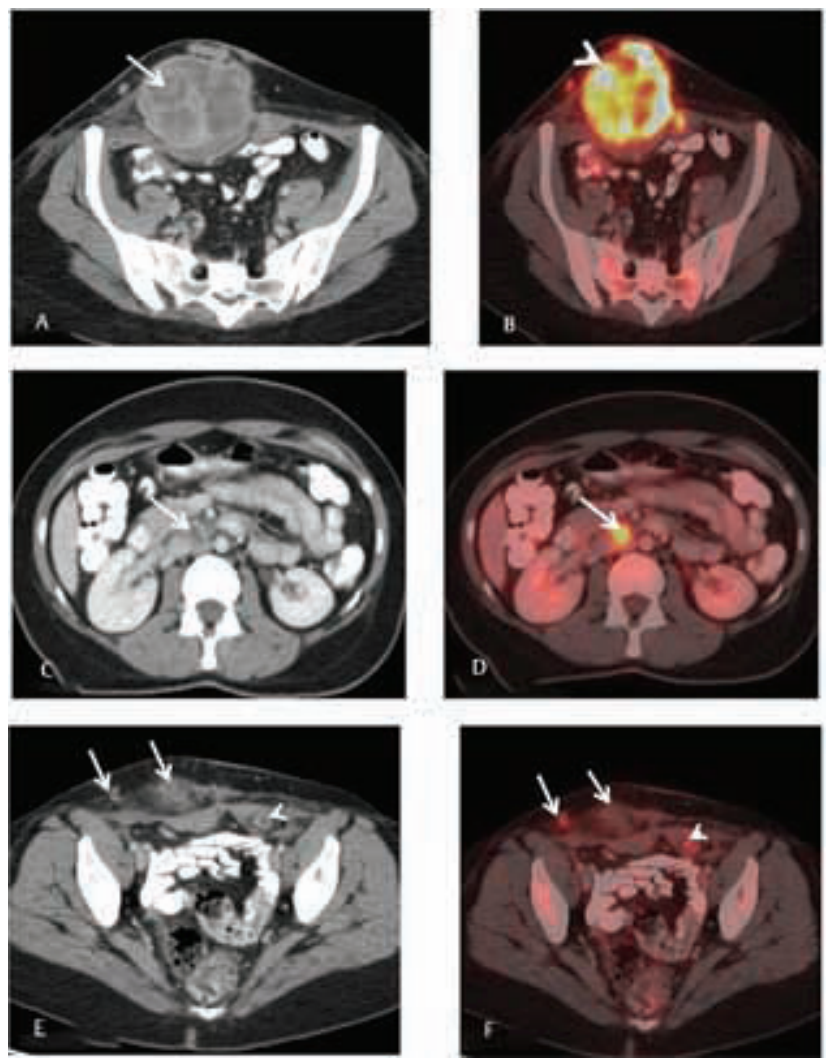

Fig. 7 (A, B) After 1 year-enlargement in the size of ovary $(84 \mathrm{~mm}$ $\times 80 \mathrm{~mm} \times 86 \mathrm{~mm}$ ), with complex cystic appearance (arrow) and increased PET uptake with SUV 19.7 (arrowhead). (C, D) In addition there were retroperitoneal nodes. Axial CECT at the level of renal hilum shows FDG-avid para-aortic nodes (arrow) suggesting metastatic lymph nodes. (E, F) Axial PET CT at the level of pelvis also showed other peritoneal (arrowhead) and abdominal wall deposits (arrow), suggesting disseminating disease. CECT, contrast-enhanced computed tomography; CT, computed tomography; FDG, fluorodeoxyglucose; PET, positron emission tomography.

lesions, 12 patients had stage III to IV endometriosis, 4 had myoma of uterus, and 1 had dysfunctional uterine bleeding. ${ }^{5}$ The short-term and long-term endocrine function of the translocated ovary remained normal in benign as well as malignant lesions.

Ovarian exteriorization was first described by Kovasev in the setting of carcinoma. This has been successfully done in 27 patients with no major complications and this may be the preferred option if ovarian preservation is planned. ${ }^{6}$

The advantages of subcutaneous implantation are early detection of complications, easy surgical access to cyst removal, and facilitation of in vitro fertilization. The first-ever reported case of ovarian hyperstimulation and percutaneous aspiration of oocytes from a transpositioned right ovary is from India. Global literature survey has shown published case reports of transabdominal aspiration for retrieval but none using percutaneous technique, resulting in a successful pregnancy. $^{2}$

Complications described in transposed ovary are ovarian cysts, ovarian edema, ovarian torsion, peritoneal inclusion cysts, and, rarely, ovarian failure and metastasis.
There are very few reported cases of ovarian torsion after transposition. Enlargement of the ovary from ovarian stimulation and an elongated vascular pedicle were thought to be contributing factors in these cases. ${ }^{6}$ Extensive ovarian mobilization can also predispose to torsion. ${ }^{7}$ Peritoneal inclusion cysts can form because of postoperative adhesions, seen with lateral transposition of ovaries.

The risk of malignancy is rare, approximately $2 \%$ in the transposed ovary, more in adenocarcinoma and in tumors involving the uterine body with lymphovascular invasion. Sutton et al reported that incidence is $0.5 \%$ in squamous cell carcinoma, compared with $1.6 \%$ for adenocarcinoma. ${ }^{1}$ However, it is uncommon in early stage cervical cancers.

Systematic review of 24 cases by Gubbala et al in 2014, with lateral ovarian transposition, shows that there is fairly good preservation of ovarian function, with only an acceptable risk of ovarian cysts and low risk of metastasis in transposed ovaries. ${ }^{1}$

\section{Conclusion}

The main purpose of ovarian transposition is to preserve fertility in those with early cancer or benign conditions like severe refractory endometriosis. Subcutaneous implantation compared with the lateral transposition highlighted here provides easy surgical access to remove the ovary in case of any complication.

The transposed ovaries can be stimulated to produce follicles and ovum and can later be retrieved under ultrasound guidance from the new sites, be it paracolic gutter or anterior abdominal wall. In vitro fertilization and embryo transfer can be done into a surrogate uterus, allowing a patient to have her own biological child in cases of early malignancy.

Laparoscopic ovarian transposition is a simple, safe, effective, and a forgotten procedure for young premenopausal patients receiving radiotherapy. ${ }^{4}$ This novel technique can be safely done in properly selected cases to preserve fertility and, hence, should be encouraged. The complications highlighted here are very rare and should not defer one from choosing the procedure.

\section{Ethical Approval}

Written informed consent was obtained from the patient for publication of this case report and any accompanying images.

\section{Authors' Contributions}

T.P. was involved with analysis and interpretation of data for the work, revising it critically for important intellectual content, and giving final approval of the version to be published. C.K. was involved with analysis and interpretation of data for the work, revising it critically for important intellectual content, and giving final approval of the version to be published. M.J.A.J. was involved with substantial contributions to the design of the work, analysis and interpretation of data for the work, drafting the work, and revising it critically for important intellectual 
content. D.C. and V.A.K. were involved with analysis and interpretation of data for the work.

\section{Funding}

None.

\section{Conflict of Interest}

None declared.

\section{References}

1 Gubbala K, Laios A, Gallos I, Pathiraja P, Haldar K, Ind T. Outcomes of ovarian transposition in gynaecological cancers; a systematic review and meta-analysis. J Ovarian Res 2014;7:69

2 Selvaraj P, Selvaraj K, Gangadharan C, Annigeri V, Srinivasan K, Sivakumar M. India's first successful surrogate birth after percutaneous oocyte retrieval following modified radical hysterectomy and right ovarian transposition to the anterior abdominal wall.J Hum Reprod Sci 2019;12(3):262-266
3 Welsh LC. Impact of pelvic radiotherapy on the female genital tract and fertility preservation measures. World J Obstet Gynecol 2014;3(2):45-53

4 Winarto H, Febia E, Purwoto G, Nuranna L. The need for laparoscopic ovarian transposition in young patients with cervical cancer undergoing radiotherapy. Int $\mathrm{J}$ Reprod Med 2013;2013:173568

5 Guo Y, Shen W, Jiang Y, Liu W, Li X. Application of ovarian transposition during hysterectomy. Chin Med J (Engl 2003;116(5):688-691

6 Simstein R, Merenich W, Graber J, Ferrell M. A case report of ovarian torsion following ovarian transposition for cervical cancer. Emerg Radiol 2020;27(5):569-572

7 Gómez-Hidalgo NR, Darin MC, Dalton H, et al. Ovarian torsion after laparoscopic ovarian transposition in patients with gynecologic cancer: a report of two cases. J Minim Invasive Gynecol 2015;22(4):687-690 